stroke unit. Once patients are medically stable, they should be transferred to a stroke rehabilitation unit if further

rehabilitation is required. Formal rehabilitation in a stroke unit is associated with reduced death and disability $(\mathrm{NNT}=12)$ and a shorter stay in hospital. Optimal care is multidisciplinary: doctors, nurses, physiotherapists, occupational therapists, speech and language therapists, dieticians, psychologists, and social workers all have a role.

\section{Secondary prevention}

Secondary prevention (apart from blood pressure control) should start shortly after admission. All patients should be offered lifestyle guidance, including advice to stop smoking, reduce saturated fat and salt consumption and alcohol intake, lose weight, and increase exercise. Aspirin started for the treatment of acute ischaemic stroke should be continued indefinitely for secondary prevention. The use of alternative or additional antithrombotic drugs (dipyridamole, clopidogrel, and warfarin), carotid endarterectomy, and management of hypertension and hyperlipidaemia after stroke are discussed in the next article in the series.

\section{The future}

Stroke management is now supported by good quality evidence, but many questions remain unanswered. Whenever possible, patients should be given the opportunity to enrol in randomised trials of acute interventions, rehabilitation, or secondary prevention.

The magnetic resonance image was provided by Professor Alan Moody, University of Nottingham. The data on thrombolysis were provided by Dr Joanna Wardlaw, University of Edinburgh.
Healthcare professionals, patients, and carers can obtain further information about strokes from the Stroke Association (020 7566 0300), Chest, Heart and Stroke Association Scotland (0131 225 6963), Chest, Heart, and Stroke Association Northern Ireland (01232 320184), or Different Strokes (01908 236033)

\section{Further reading}

- Bath PMW. The medical management of stroke. Int J Clin Pract 1997;51:504-10.

- Lees KR. If I had a stroke... Lancet 1998;352 (suppl III):28-30.

- Royal College of Physicians. Stroke audit package. London: RCP, 1994.

- Stroke Units Trialists' Collaboration. Collaborative systematic review of the randomised trials of organised inpatient (stroke unit) care after stroke. BMJ 1997;314:1151-9.

Philip M W Bath is professor of stroke medicine, University of Nottingham, and Kennedy R Lees is professor of cerebrovascular medicine, university department of medicine and therapeutics, Western Infirmary, Glasgow.

The ABC of arterial and venous disease is edited by Richard Donnelly, professor of vascular medicine, University of Nottingham and Southern Derbyshire Acute Hospitals NHS Trust (richard.donnelly@ nottingham.ac.uk) and Nick J M London, professor of surgery, University of Leicester, Leicester (sms16@leicester.ac.uk). It will be published as a book later this year.

BMJ 2000;320:920-3

\section{My most valuable lesson}

\section{A full examination is always useful}

It happened two weeks ago. One of the patients attending the unit that day was a man who had received an allogeneic stem cell transplant nine months earlier. He presented with a 24 hour history of right sided chest pain which seemed to be temporally related to a recent bout of coughing.

The patient duly undressed to the waist and I performed a respiratory examination, starting with assessment of chest expansion. My gaze fixed in the direction of my thumbs, I detected no abnormality. Tracheal position central. Tactile vocal fremitus and percussion were normal over the anterior and lateral chest. Auscultation was unremarkable in these areas. Moving to the patient's back there were no new chest signs to be elicited, although my attention was briefly drawn to a small group of reddish papules in the skin overlying the vertebral process of T8. Finally I discovered some local tenderness in the area of the patient's discomfort, blindly palpating his right lateral chest wall, and diagnosed an intercostal muscular strain secondary to coughing. I told the consultant of my findings, and he came to see the patient himself.

Courtesy dictated that I should remain in attendance while the repeat assessment took place. The patient's shirt was once more removed whereupon my boss took a discernible step backwards (advice given to me repeatedly when I was preparing for my membership examination) and then inspected the chest wall with the patient's right arm raised.

My pen almost fell out of my hand, poised as it was over the case notes. There, in full view, was a narrow, intermittent row of papules, conforming to an arc extending between the patient's back and right anterior axillary line.
My consultant turned back to me, directing a quizzical look in my direction; I suspect it was met by my own open mouthed, disbelieving one. His words were spoken quietly and distinctly, but they shook me like thunder:

"It's zoster, isn't it?"

Alexander Pope wrote, "A man should never be ashamed to own he has been in the wrong, which is but saying, in other words, that he is wiser today than he was yesterday."

I now have proof, if I needed it, that clinical examination technique has enormous relevance to our everyday practice. Furthermore, after the intense embarrassment I suffered on that fateful day, I now find myself in the new, liberated position that, if I am ever inclined or encouraged to criticise a colleague's clinical oversight in the future, I need only to bring to mind my patient with his dermatomal eruption.

Richard J A Murrin specialist registrar in haematology, Birmingham

We welcome articles of up to 600 words on topics such as A memorable patient, A paper that changed my practice, My most unfortunate mistake, or any other piece conveying instruction, pathos, or humour. If possible the article should be supplied on a disk. Permission is needed from the patient or a relative if an identifiable patient is referred to. We also welcome contributions for "Endpieces," consisting of quotations of up to 80 words (but most are considerably shorter) from any source, ancient or modern, which have appealed to the reader. 